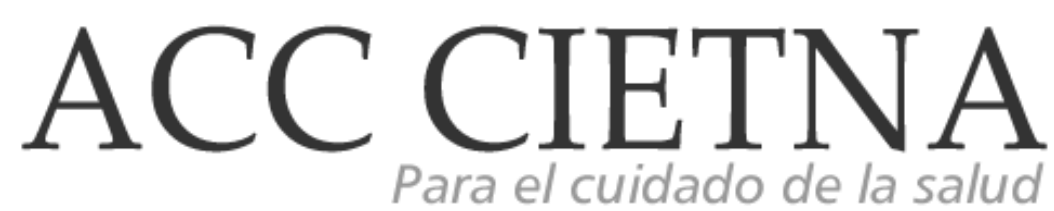

\title{
Lesões por Esforço Repetitivo/Distúrbio Osteomuscular Relacionado ao Trabalho: contribuições para a prevenção em trabalhadores de enfermagem
}

\author{
Assis de Paula Ana de ${ }^{1}$, Ortiz Sanchez Maritza Consuelo ${ }^{2}$, Pereira Marilia de Jesus ${ }^{3}$
}

\begin{tabular}{l} 
INFORMACIÓN DEL ARTÍCULO \\
\hline Historia del artículo: \\
Recibido el 23 de mayo de 2016 \\
Aceptado el 15 de octubre de 2016
\end{tabular}

Palabras claves:

Lesiones por Esfuerzo

Repetitivo/Disturbio

\section{RESUMEN}

Esta investigación analizó el conocimiento de los profesionales de enfermería sobre las medidas de prevención de las Lesiones por Esfuerzo Repetitivo/Disturbio Osteomuscular Relacionado al Trabajo. Estudio de abordaje cualitativo y descriptivo, cuyos participantes fueron diez enfermeros de una Clínica Escuela de Enfermería. Recolecta de datos: entrevista semiestruturada. En el análisis emergieron dos categorías temáticas: Conocimientos sobre Lesiones por Esfuerzo Repetitivo/Disturbio Osteomuscular Relacionado al Trabajo; Medidas Preventivas sobre Lesiones por Esfuezo Repetitivo/Disturbio Osteomuscular Relacionado al Trabajo: contribuciones para enfermería. En los resultados fue posible vislumbrar que los entrevistados tienen conocimiento sobre el problema y sus formas de prevención. En lo que respecta a la prevención esta debe estar dirigida a cambios de postura en la ejecución de las actividades, mobiliarios, instrumentos y equipos adecuados al desempeño de las tareas y adopción de programas de entrenamiento. Conclusiones: los entrevistados mostraron conocimiento sobre esta problemática y sus formas de prevención; sin embargo, con la finalidad de profundizar es necesario educación continuada sobre la temática y adopción de programas de entrenamiento, con la finalidad de establecer estrategias para evitar el riesgo ocupacional y disminuir la probabilidad de enfermarse.

\footnotetext{
${ }^{1}$ Enfermeira do Trabalho em Hospital Estadual Rocha Faria. Rio de Janeiro, Brasil. ORCID: https://orcid.org/ 0000-0001-8170-6352

2 Doutora em Enfermagem, Professora Adjunta do Departamento de Enfermagem Fundamental e Administração da Escola de Enfermagem Aurora de

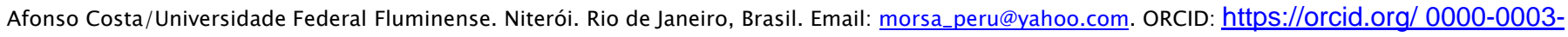
$\underline{0131-9489}$

${ }^{3}$ Mestre em Enfermagem, Professora Assistente da Faculdade Cenecista de Rio das Ostras. Rio de Janeiro, Brasil. ORCID: https://orcid.org/ 0000-00017084-7109
} 
Repetitive Strain Injuries/Musculoskeletal Disorders Related to Work: contributions to the prevention of nursing professionals

ABSTRACT

Keywords:

Repetitive Strain Injuries /

Musculoskeletal

Disorders Related to Work. Worker's health.

Occupational

hazards. Nursing
This research analyzes the knowledge of nursing professionals on the prevention of Repetitive Strain Injury / Work-Related Musculoskeletal Disorders. Study of qualitative and descriptive approach, whose participants were ten nurses in a Clinical School of Nursing. Data collection: semi-structured interview. In the analysis emerged two thematic categories: Understanding Repetitive Strain Injury / WorkRelated Musculoskeletal Disorders; Preventive measures on Repetitive Strain Injury / Work-Related Musculoskeletal Disorders: contributions to nursing. The results was possible to see that the respondents have knowledge about the problem and its prevention. As concerns the prevention this should be directed to postural changes in the implementation of activities, securities, instruments and equipment suitable for the performance of tasks and adoption of training programs. Conclusions: The respondents showed knowledge of this problem and its prevention; however, for the purpose of deepening is necessary continuing education on the subject and adoption of training programs, in order to establish strategies to prevent occupational risk and decrease the likelihood of becoming ill.

\section{Introdução}

O presente trabalho teve por objeto de estudo o conhecimento dos profissionais de enfermagem de uma Clínica Escola sobre prevenção das Lesões por Es f or ço Repet i t i vo/ Di s t úr bi o Os t eomus cul ar Rel aci onado ao Tr abal ho (LER/ DORT). Os distúrbios osteomusculares têm se tornado casa vez mais comuns, sendo considerados um dos maiores problemas de saúde ocupacionais do mundo. Este problema leva trabalhadores a diferentes graus de incapacidade funcional, devido à exposição contínua e prolongada do corpo aos fatores de risco presentes no ambiente de trabalho que favorecem o surgimento das doenças ocupacionais, ocasionando afastamentos temporários ou permanentes do trabalhador ${ }^{1,2}$.

Segundo dados do Instituto Nacional de Seguridade Social (INSS) de acordo com a Organização Mundial de Saúde (OMS), um em cada
100 trabalhadores do Sudeste brasileiro é portador de LER/DORT. E, somente no primeiro ano de afastamento, cada funcionário vitimado pelas LER/DORT acarreta para a empresa, em média, uma despesa de $R \$ 89$ mil, entre encargos sociais e pagamento de substituto temporário. O custo dos acidentes de trabalho e doenças ocupacionais para as empresas é de $R \$ 12,5$ bilhões/ano, e, para o país, de R\$20 bilhões/ano (aposentadoria, indenizações e tratamento médico) ${ }^{3}$.

A incidência desta patologia varía de acordo com a atividade ocupacional, assim como apresenta diferenças entre indivíduos que executam uma mesma atividade ocupacional, ainda que dentro de uma mesma empresa. Entretanto, observa-se que não há aumento crescente de LER/DORT em pessoas em faixas etárias mais elevadas, quando comparadas com os jovens que exercem a mesma profissão 4 . 
Estudos mostram que a LER/DORT é mais frequente no sexo feminino, não havendo diferenças raciais ou sociais, sendo menos comum no trabalhador autônomo. Com relação ao maior número em mulheres, isto pode estar relacionado à natureza do trabalho que desempenham, à dupla jornada de trabalho e às condições orgânicas. Além disso, com o aumento da idade, aumenta a suscetibilidade $4,5$.

A literatura destaca os trabalhadores da saúde como grupo de risco para o desenvolvimento de LER/DORT. Dentre esses, a enfermagem é a que concentra maior força de trabalho e a que mais está exposta a riscos advindos de sua profissão, com prevalência entre 43 a 93\% desses distúrbios 6 , 7.

O trabalho dos enfermeiros é estressante em função da forte carga psicoemocional, decorrente da relação enfermeiro-paciente, e dos turnos prolongados. Esses profissionais desenvolvem suas tarefas em diversos locais e realizam atividades de forma contínua, que exigem constante atenção, esforço físico, posições inadequadas, movimentos repetitivos e levantamento de peso, o que os predispõem ao risco de adoecimento pelo trabalho ${ }^{7}$.

Neste contexto, vários são os fatores que contribuem para a ocorrência de LER/DORT entre esses profissionais, que incluem não apenas a precariedade das condições do ambiente de trabalho (recursos tecnológicos inadequados, falta de equipamentos especiais para movimentar pacientes, além da escassez de recursos humanos e a falta de treinamento), mas as próprias atribuições da profissão, em que se observa repetição de atividades, sobrecarga e aceleração do ritmo de trabalho, decorrentes de funções próprias da assistência de enfermagem (higiene dos pacientes, arrumação de leitos, realização de curativos, transporte e manipulação de pacientes), entre outras, assim como de procedimentos administrativos: preenchimento de impressos, anotações em prontuário, elaboração de escalas e gráficos, informatização dos prontuários, atividades estas que podem contribuir para a ocorrência de distúrbios osteomusculares ${ }^{8}, 9$.

Uma pesquisa realizada na rede Hospitalar do Estado de Minas Gerais visando relacionar os problemas de saúde encontrados em trabalhadores de enfermagem de 23 instituições de saúde trouxe o seguinte resultado: de 6.070 atendimentos, 255 ( 35\%) correspondeàs doenç as legal mente consideradas como doenças do trabalho relacionadas ao sistema musculoesquelético; $20 \%$ correspondem às dorsalgias e as $\mathrm{s}$ i novi $\mathrm{t}$ es ; e 13,7\% às tenossinovites 7,8 .

Em um levantamento dos afastamentos por motivo de saúde dos trabalhadores de enfermagem de um hospital público foi observado que as doenças osteomusculares são a terceira causa de afastamento, e ocupam o segundo lugar na análise do quantitativo de dias de afastamento ${ }^{10}$.

Out $r$ a pes qui $s$ a apont ou que os probl emas musculoesqueléticos ligamentares responderam por $36,3 \%$ dos períodos de licença, por $100 \%$ dos casos de licença por período indeterminado e por $25,5 \%$ do total de dias computados de ausência ao trabalho.

Ainda assinalou que $62,9 \%$ dos trabalhadores entraram em licença-saúde, e o período mais frequente de afastamento abrangeu de 1 a 5 dias $^{11}$.

No que diz respeito ao absenteísmo, a equipe de enfermagem é a categoria com maior número de licenças médicas para afastamento do exercício profissional, sendo as doenças osteomusculares e do tecido conjuntivo a principal razão ${ }^{12}$.

Um estudo mostrou a exposição dos profissionais de enfermagem do Hospital Universitário Pedro Ernesto (HUPE), da cidade do Rio de Janeiro, aos fatores de risco das LER/DORT e os resultados evidenciaram que estes profissionais estão expostos a vários fatores de risco, principalmente os de naturez a organizacional e ergonômica. $\mathrm{O}$ 
estudo concluiu que as condições de trabalho inadequadas, no que tange à organização do trabalho e à inobservância dos princípios ergonômicos, propiciam a manifestação de LER/DORT nos trabalhadores ${ }^{6}$.

No que diz respeito às estratégias preventivas ao surgimento de LER/DORT estão incluídas a educação em saúde, que tem por foco a reeducação postural e gestual no trabalho, sendo de suma importância a compreensão e a assimilação individual a respeito desses cuidados no dia a dia, bem como a adoção de critérios de ergonomia. Estas táticas visam não apenas a melhoria dos postos de trabalho, mas também a eliminação (ou ao menos, a amenização) dos fatores de risco, tais como transporte e manuseio de cargas, moderação dos movimentos repetitivos e reorganização do ambiente, com vistas à eliminação de posturas e movimentos críticos $^{13}$.

Diante das considerações acima expostas elaborou-se o seguinte objetivo: analisar o conhecimento dos profissionais de enfermagem sobre as medidas de prevenção de LER/DORT.

Esta pesquisa se justifica tendo em vista a necessidade de aprofundar o conhecimento sobre as LER DORT e pr opi ci ar no pr of i ssi onal de enfermagem uma reflexão sobre suas condições de trabalho, na tentativa de minimizar os riscos aos quais se encontram expostos. Além disso, o mesmo visa preencher lacunas existentes nesta área de saber.

\section{Metodología}

O método utilizado para a realização desta pesquisa foi o de abordagem qualitativa, que permite a discussão de fatos que ocorrem em uma dada realidade. A pesquisa qualitativa considera que há uma relação dinâmica entre o mundo real e o sujeito, isto é, um vínculo indissociável entre o mundo objetivo e a subjetividade do sujeito que não pode ser traduzido em números ${ }^{14}$. A interpretação dos fenômenos e a atribuição de significados são básicas no processo de pesquisa qualitativa. O ambiente natural é a fonte direta para coleta de dados e o pesquisador é o instrumento-chave.

Consistiu ainda em um estudo descritivo, na medida em que o interesse da pesquisa estava voltado para a análise de uma determinada realidade. A pesquisa descritiva tem por objetivo principal descrever, analisar ou verificar as relações entre fatos e fenômenos (variáveis), ou seja, tomar conhecimento do que, com quem, como e qual a intensidade do fenômeno em estudo; meio pelo qual assimdescrevemos 0 conhecimento dos profissionais de enfermagem sobre as medidas preventivas ao surgimento de LER/DORT ${ }^{15}$.

Os participantes do estudo foram constituídos por 10 (dez) enfermeiros que trabalhavam em uma Clínica Escola de Enfermagem. A escolha dos colaboradores foi realizada de forma aleatória, através de contato pessoal com os participantes, quando foi indagado se os mesmos gostariam de participar da pesquisa.

A coleta de dados foi realizada por meio de entrevista individual com os colaboradores, através de um roteiro previamente elaborado. Cabe destacar que a entrevista é uma técnica em que $o$ investigador se apresenta frente ao investigado e formula perguntas, com o objetivo de obtenção dos dados que interessam à investigação. Permite o desenvolvimento de uma estreita relação entre as pessoas e é um modo de comunicação no qual determinada informação é transmitida de uma pessoa para outra ${ }^{15,16 .}$

Utilizou-se neste estudo a entrevista semiestruturada, que é uma combinação de perguntas abertas, em que o entrevistado discorre sobre o assunto em questão sem se prender às questões formuladas, e perguntas fechadas. A entrevista semiestruturada tem como característica a utilização de questionamentos básicos, que são apoiados em teorias e hipótesis 
relacionados ao tema da pesqui sa e cujos questionamentos dariam frutos a novas hipóteses, surgidas a partir das respostas dos informantes. Este tipo de entrevista favorece não só a descrição dos fenômenos sociais, mas também a sua explicação e a compreensão de sua totalidade ${ }^{17}$.

Portanto, na entrevista foram utilizadas questões onde o entrevistado teve a possibilidade de discorrer sobre o assunto apresentado, sem respostas ou condições pré-fixadas pela pesquisadora.

$\mathrm{Na}$ abordagem aos colaboradores do estudo, a pesquisadora realizou uma breve exposição sobre o objetivo e finalidade da pesquisa, colocando-se à disposição para os esclarecimentos necessários. Cabe ressaltar que a coleta de dados foi precedida pela leitura explicativa do Termo de Consentimento Livre e Esclarecido e, realizada apenas após a concordancia dos colaboradores em participar da pesquisa, sendolhes asegurado o sigilo, o anonimato e o direito de desistirem da participação em qualquer etapa da pesquisa, de acordo com a Resolução $n^{\circ}$ 466/12 do Conselho Nacional da Saúde (CNS) ${ }^{18}$.

Neste sentido, os procedimentos adotados visaram propiciar a criação de condições para a participação efetiva dos envolvidos, buscando o estabelecimento de um clima de confiança e respeito, na interação entre pesquisador e colaboradores, enfatizando a cooperação mútua, o engajamento, o compromisso e a participação como determinantes para o resultado da pesquisa.

análise de conteúdo do tipo temática. A análise de conteúdo trata-se de um conjunto de técnicas de análise de comunicação que visa verificar hipótesis e/ou descobrir o que está por trás de cada conteúdo manifesto. A análise temática, por sua vez, é uma das técnicas de análise de conteúdo caracterizada pela presença de determinados temas que tem por significado "os valores de referência e os modelos de comportamento presentes no discurso" 14 .
Operacionalmente, a análise de conteúdo envolve as seguintes etapas: pré-análise, exploração do material, tratamento dos resultados obtidos $\mathrm{e}$ interpretação. Na primeira etapa foi realizada a leitura e releitura do material coletado para impregnação de seu conteúdo, com o objetivo de organizar o material a ser analisado; neste momento, foram definidas as uni dades de regist ro, de contexto, trechos significativos e as categorias, considerando os objetivos da pesquisa. A segunda etapa consistiu basicamente na operação de compilação do material organizado na primeira fase, quando são escolhidas as categorias teóricas ou empíricas que darão a especificidade aos temas. Já na terceira e última etapa, as informações obtidas foram evidenciadas, a partir de inferências e interpretações do pesquisador à luz da literatura utilizada ${ }^{14,19}$.

\section{Resultados e Discussão}

Ao realizar a análise dos dados duas categorias temáticas emergiram: Entendimento sobre LER/ DORT; e Medidas Preventivas sobre LER/DORT: contribuições para a enfermagem.

\subsection{Entendimento sobre LER/DORT}

$O$ ent endi ment o mani fest ado por part e dos participantes da pesquisa sobre LER/DORT foi descrito segundo os depoimentos a seguir: "É um distúrbio osteomuscular" (Entrevista 1). "São distúrbios osteomusculares" (Entrevista 2). "É uma lesão causada por esforços repetitivos" (Entrevista 5) "É uma lesão por trauma cumulativo" (Entrevista 7) Os colaboradores do estudo também inferiram que a LER/DORT se apresenta sob diversas formas clínicas, algumas delas evidenciadas pelas falas detalhads na continuação: "Bursite, tendinite, dor lombar" (Entrevista 1). "Tendinite, síndrome do túnel do carpo" (Entrevista 2).

"(...) lombalgia" (Entrevista 4).

"(. . ) I ombal gi a, i nf I amação nos cot ovel os" (Entrevista 6).

"Tendinite, hérnia de disco, dores musculares." (Entrevista 9). 
Quanto aos principais fatores predisponentes ao surgimento das manifestações clínicas de LER/ DORT a pont a dos pelos entrevistados, identificou-se a repetitividade de movimentos, postura inadequada, esforço físico excessivo e jornada de trabalho prolongada, como podemos observar nos seguintes discursos:

"Repetitividade de movimentos, posturas inadequadas por tempo prolongado, impacto, vibração e frio, esforço físico e a invariabilidade das tarefas" (Entrevista 1).

"Movimentos repetitivos, postura inadequada, esforço excessivo" (Entrevista 2).

"Trabalhos repetitivos, má postura, jornada de trabalho prolongada (...)" (Entrevista 4).

"Trabalhos repetitivos, ritmo intenso de trabalho, manutenção de postura por longo tempo (...)" (Entrevista 8).

Um ponto interessante apontado pelos participantes na rotina laboral refere-se ao estresse como outro fator predisponente à instalação das LER/DORT:

“(...) o estresse também, eu vim pra aqui, descansei menos do que deveria por que estava fazendo plantão, o estresse do trânsito, a rotina... tudo isso contribui." (Entrevista 1)

"(...) o excesso de trabalho, carga horária; às vezes trabalho seis horas aqui e, no outro emprego, oito horas, mais um plantão em outro lugar, isso é o estresse no trabalho, né." (Entrevista 5)

"(...) tem o fator estressante, do trabalho em si, das outras pessoas, que acaba te deixando irritada (...)" (Entrevistado 2).

"(...) a gente vem de uma rotina estressante, de varias pessoas que adoecem, aqui e em outros plantões, e aí tem pouca gente para atender..., aqui somos duas por escala, e não é muito diferente em outros locais, e dependendo da época do ano piora... o trabalho em pé, andar para lá e para cá, o dia a dia [...] tem o estresse do trânsito" (Entrevista 9)

Em relação a sua rotina de trabalho, as principais atividades realizadas pelos profissionais entrevistados estão relacionadas à consulta de enfermagem, realização de procedimentos de enfermagem, orientação de alunos de enfermagem, realização de atividades burocráticas (requisição de mat eri ai s, el aboração de escal as, anot ações, digitação) e organização do ambiente (limpeza de armários, reposição de materiais, arrumação dos consultórios), como confirmam as falas a seguir:

"[...] arrumação do ambiente, realização de curativos, transporte e manipulação de pacientes (...)" (Entrevista 1).

“(..) monitoramento do paciente, anotação em prontuários, mudança de decúbito, repor soro (...)" (Entrevista 3).

"(...) realização de procedimentos, arrumar os consultórios, orientar os alunos (...)"

(Entrevista 9).

“(...) limpar os armários, repor gavetas, requisitar materiais, elaborar escalas (...)"

(Entrevista 10).

\subsection{Medidas preventivas para LER/DORT: contribuições para a enfermagem}

As medi das de pr evenção das LER/ DORT compreendem reestruturações no processo produtivo que resultem em melhoria da qualidade de vida dos profissionais, proporcionando maior identidade com a tarefa, maior autoridade sobre o processo e a eliminação de posturas extremamente rígidas, normalmente existentes nas relações ou no método de trabalho20.

Nesse sentido, os depoentes desta pesquisa referiram que a amenização de esforços físicos repetitivos, o mobiliário adequado dos postos de trabalho, as pausas durante os afazeres, entre outros, contribuem para a diminuição das LER/DORT:

"(...) amenização dos esforços físicos repetitivos, mobiliário adequado dos postos de trabalho." (Entrevista 1)

"Pausas durante o trabalho, evitar posturas incorretas, adequação do mobiliário."

(Entrevista 2) 
"Pausas durante a escala, adequação do mobiliário e equipamentos para evitar posturas

inadequadas." (Entrevista 5)

"Seria bom orientações sobre adoção de posturas corretas (...)" (Entrevista 10)

\subsection{Quanto ao entendimento sobre LER/DORT:} Compreende-se por LER/DORT as alterações musculoesqueléticas por uso repetido ou manutenção de postura inadequada ${ }^{21}$, que afetam músculos, tendões, sinóvias (revestimentos das articulações) nervos, fáscias (envoltório dos músculos) e ligamentos, isolados ou combinados, com ou sem a degeneração de tecidos, voltados ao trabalho20. São considerados transtornos funcionáis ocasionados pela utilização biomecanicamente incorreta dos membros superiores que resultam em dor, fadiga, queda de desempenho no trabalho, incapacidade temporária e, conforme o caso, pode evoluir para uma síndrome dolorosa crônica ${ }^{22}$.

No Brasil, a síndrome de origem ocupacional, composta de afecções que atingem os membros superiores, região escapular e pescoço, foi reconhecida pelo Ministério da Previdência Social como Lesões por Esforços Repetitivos (LER), por meio da Norma Técnica de Avaliação de Incapacidade (1991)'.Posteriormente com a revisão dessa norma, foi introduzida a expressão

Distúrbios Osteomusculares Relacionados ao Trabalho (DORT).

A Norma Técnica do Instituto Nacional do Seguro Social (INSS), Ordem de Serviço 606 de 05/08/1998 conceitua LER/DORT como uma síndrome clínica caracterizada por dor crónica, acompanhada ou não por alterações objetivas, e que se manifesta principalmente no pescoço, cintura escapular e/ou membros superiores em decorrência do trabalho, podendo afetar tendões, músculos e nervos periféricos ${ }^{23}$.

A expressão LER/DORT não é fruto exclusivo de movimentos repetitivos, mas podem ocorrer pela per manênci a de $s$ egment os do cor po em determinadas posições, por tempo prolongado. A necessidade de concentração e atenção do trabalhador para realizar suas atividades e a pressão imposta pela organização do trabalho são fatores que interferem significativamente para a ocorrência da síndrome².

Considerando o entendimento por parte dos entrevistados sobre LER/DORT, o mesmo mostrase condizente com a literatura, que define LER/DORT como uma síndrome relacionada ao trabalho, de origem multifatorial, decorrente da combi nação da $s$ obr ecarga das es $t r$ ut ur as anatômicas do sistema osteomuscular com a falta de tempo para sua recuperação, e caracterizada pela ocorrência de vários sintomas concomitantes ou não, tais como dor, parestesia, sensação de peso, fadiga, de aparecimento insidioso, geralmente nos membros superiores, mas podendo acometer membros inferiores ${ }^{1,21 .}$

Quanto às principais formas clínicas de LER/ DORT, al gumas del as t ambém foram apontadas pelos participantes da pesquisa, as quais, segundo o referencial teórico, são: Tendinites e tenossinovites, consideradas doenças inflamatórias que comprometem as bainhas tendíneas e os tendões em decorrência das exigências do trabalho.

Nos casos mais crônicos ocorrem alterações degenerativas. A tenossinovite surge do atrito excessivo de tendão que liga o músculo ao osso. Essas afecções são mais frequentes na população de risco, ematividades que exigem grande repetitividade juntamente com força. $\mathrm{O}$ sintoma mais característico é a dor; se subdividem em:

tendinite; tendinite do supra- espinhoso; tenossinovite estenosante de dequervain; dedo em gatilho; tenossinovite dos flexores dos dedos e dos flexores do carpo; tenossinovite dos extensores dos dedos; epicondilite $20,22$.

Já os Cistos sinoviais são tumefações esféricas, geralmente únicas, macias, habitualmente indolores e flutuantes que ocorrem por 
degeneração mixóide do tecido sinovial periarticular ou peritendíneo. São comuns na face extensora do carpo, podendo ter o seu aparecimento favorecido por trabalhos manuais que exijam força22.

As Ne u ro patias compressivas perif é r i c a s compreendem a síndrome do desfiladeiro torácico, síndrome do supinador, síndrome do pronador redondo, síndrome do interósseo anterior, síndrome do túnel do carpo, síndrome do canal de Guyon e síndrome cervicobraquial20, 22.

A Síndrome dolorosa miofascial é uma condição dolorosa muscular regional, caracterizada pela ocorrência de dor muscular localizada ou referida, pontos gatilhos, bandas de tensão, reprodução da dor por digito pressão e reação muscular contrátil localizada. Os pontos-gatilho quando estimulados por palpação digital, geram dor localmente, à distância ou referida. Acomete músculos, tecidos conjuntivos e fáscias, principalmente na região cervical, cintura escapular e lombar. Pode ter inst alação gradual em decorrência de microtraumatismos repetitivos durante a execução de atividades diárias ou do trabalho, resultando em fadiga ou sobrecarga ${ }^{23,24}$.

Por fim, a Fibromialgia é uma síndrome dolorosa crônica não inflamatória, caracterizada pela presença de dor difusa pelo corpo, sensibilidade exacerbada à palpação de determinados sítios denominados pontos dolorosos (tender points), fadiga, distúrbios do sono e do humor. A fadiga muscular na fibromialgia não foi totalmente explicada, pode ser ocasionada por anormalidades de distribuição de energia, alterações histológicas, incapacidade de relaxamento do músculo e pela redução do fluxo sanguíneo 25 .

Os colaboradores do estudo identificaram varios fatores associados ao trabalho que concorrem para a o corrência de LER/DORT, t a i s co mo a repetitividade de movimentos, a manutenção de post ur as i nadequadas, o esf or ço fí si co, a invariabilidade de tarefas, a pressão mecânica sobre determinados segmentos do corpo, o trabalho muscular estático, impactos e vibrações. A intensificação do ritmo, da jornada e da pressão por produção e a perda acentuada do controle sobre o processo de trabalho por parte dos trabalhadores (fatores relacionados à organização do trabalho),também têm sido apontados como os principais determinantes para a disseminação da doença 22, 4, 20.

Caracterizados como os principais fatores de risco relacionados à ocorrência de LER/DORT entre os profissionais de enfermagem, é importante então considerar: a organização do trabalho (aumento da jornada de trabalho, jornada dupla ou trabalho sem pausas, horas extras excessivas, ritmo acelerado); os fatores ambientais (espaço restrito, mobiliários inadequados não ergonômicos falta de equipament os especiais para movimentar pacientes, iluminação insuficiente) e as possíveis sobrecargas de segmentos corporais, ocasionadas por trabalho repetitivo, movi mentaçãoe transferência de pacientes, falta de treinamento para o uso de equipamentos, técnicas e práticas de levantamento impróprias, manutenção de posturas inadequadas e estáticas, movimentos freqüentes de flexão, torção da coluna vertebral e esforço'.

Os movimentos repetitivos são reconhecidamente fatores de risco para o adoecimento por

LER/DORT, e, no trabalho de enfermagem, realizam-se diversas atividades que exigem este tipo de movimento, como por exemplo, a aferição de sinais vitais, a administração de medicamentos, as anotações em prontuários, a reposição de materiais, entre outros $20,26$.

Os procedimentos que envolvem a movimentação e o transporte de pacientes são apontados como os mais prejudiciais à saúde dos profissionais de enfermagem. São atividades físicamente desgastantes, com diferentes níveis de sobrecarga e que se tornam prejudiciais devido à má postura corporal adotada pelo profissional. Inúmeros fatores interferem na execuç ã o destes procedimentos, com destaque para o reduzido 
espaço físico, número insuficiente de profissionais, presença de equipamentos inadequados, como camas sem travas nas rodas, macas e cadeiras de rodas sem manutenção, a falta de materiais auxiliares, entre outros 24,25 .

Neste contexto, a falta de manutenção de equi pament os, a ut i I i zação de mobi I i ár i os improvisados e o déficit de pessoal também são fatores que contribuem para tornar o trabalho da enfermagem mais árduo ${ }^{24}$.

Tais fatores influenciam para que, muitas vezes, sejam exigidos do trabalhador de enfermagem empenhos superiores às suas capacidades, tanto físicas quanto emocionais e mentais. Assim como os componentes do processo de trabalho da enfermagem, principalmente a realização de atividades repetitivas, monótonas e a intensidade do esforço físico-postural5, esses esforços excessivos também podem levar ao desenvolvimento de LER/DORT20.

Sendo assi $\mathrm{m}$, conf or me menci onado pel os depoentes, a possibilidade o estresse como fator predisponente à instalação das LER/DORT é pertinente, uma vez que existem evidências de que fatores psicossociais estejam envolvidos naetiologia das LER/DORT, sejam eles relacionados ao ambiente de trabalho, ao ambiente fora dele e ao indivíduo. A interação dos três afeta o bem estar e o desempenho no trabalho, assim como agrava a condição psicológica ${ }^{27}$.

Por fim, em relação as principais tarefas realizadas pelos profissionais no ambiente de trabalho, alguns estudos apontam que as atividades de assistência direta ao paciente são as que demandam maior esforço físico e expõem os enfermeiros ao risco de desenvolver dores musculoesqueléticas $24,25$.

4.2 Quanto às medidas preventivas para LER/DORT: contribuições para a enfermagem
Ao se falar de medidas preventivas a ergonomia tem sido apontada como uma estratégia importante na redução dos problemas decorrentes de situações de trabalho que caus am doenças no sistema musculoesquelético. As condições de trabalho, para a ergonomia, representam um conjunto de fatores interdependentes, que influenciam direta ou indiretamente na qualidade de vida dos trabalhadores e nos resultados do próprio trabalho, sendo o homem, a atividade e o ambiente de trabalho os elementos que compõem a situação de trabalho'28.

A ergonomia é o estudo científico da relação entre o homem e seu ambiente de trabalho, abrangendo não apenas o local de trabalho propriamente dito, mas também os instrumentos, os métodos e a organização deste trabalho. Insere-se nessa relação a natureza do próprio homem, o que inclui suas habilidades e capacidades psicofisiológicas, antropométricas e biomecânicas ${ }^{28}$.

O sistema focalizado pela ergonomia constitui-se de componentes que interagem entre si de forma complexa. O centro desse sistema é o homem (educação, motivação, dados antropométricos), que é influenciado pela tarefa (análise da postura, vibração, aplicação de forças, repetição, ritmo e métodos de trabalho, movimentos de flexão e torção), instrumento (peso, tamanho, manejo e controles, localização) e posto de trabalho (alcance dos movimentos, espaço de trabalho, altura da superfície de trabalho, mobiliário). Ao redor desse sistema encontram-se os aspectos físicos (ruído, iluminação, temperatura) e os aspectos éticos, legais e administrativos, que podem influenciar, direta ou indiretamente, os outros componentes 29 .

Considerando as medidas preventivas para a LER/DORT sugeridas pelos colaboradores da pesquisa, estudos mostram que os ergonomistas, juntamente com a enfermagem do trabalho, podem encontrar formas adaptativas passíveis de melhorar o ambiente hospitalar, favorecendo possivelmente a saúde dos profissionais de saúde 
e diminuir a predisposição às LER/DORT. Por exemplo, durante a execução de suas atividades ocupacionais, os trabalhadores de enfermagem frequentemente têm que por ou retirar objetos (soros, roupas, monitores, caixas de instrumental, etc.) de alturas elevadas. Para evitar esse problema, é aconselhável a realização de um planejamento para o armazenamento de materiais em armários e a utilização de uma escadinha ${ }^{28}$.

Como proteção à saúde dos trabalhadores foram criadas as Normas Regulamentadoras (NR), dentre elas a NR 17 e a NR32. A NR 17 traz aspectos da ergonomia e visa estabelecer parâmetros que permitam a adaptação das condições de trabalho às características psicofisiológicas dos trabalhadores, de modo a proporcionar um máximo de conforto, segurança e desempenho eficiente ${ }^{30}$. Em relação às condições de trabalho esta norma traz aspectos relacionados a levantamento, transporte e descarga de materiais, ao mobiliário, aos equipamentos e às condições ambientais do posto de trabalho e à própria organização do trabalho.

A NR 32 tem por finalidade estabelecer diretrizes básicas para a implementação de medidas de proteção à segurança e à saúde dos trabalhadores dos serviços de saúde ${ }^{31}$. Esta norma contemplou diretrizes sobre alguns aspectos na implementação das medidas de proteção contra os riscos ocupacionais, enfocando os riscos biológicos, químicos e das radiações ionizantes. Aspectos referentes à organização dos postos de trabalho como, por exemplo, deslocamentos, esforços adicionais, movimentação e transporte de pacientes e materiais, encontram-se descritas nas Disposições Gerais da norma.

Cabe ressaltar que a adoção de medidas no sentido de indicar e orientar a prática de uma atividade de forma regular pelos trabalhadores de enfermagem faz-se necessária32. Nesse contexto, a ginástica laboral é definida como um conjunto de práticas elaboradas a partir da atividade profissional três vezes por semana, ou diariamente, por períodos que variam de 8 a 12 minutos, durante a jornada de trabalho, que visa compensar as estruturas mais utilizadas no trabalho e ativar as que não são requeridas, relaxando-as e tonificando-as. Ela atua de forma preventiva e terapêutica, e representa uma ferramenta importante ao profissional da saúde submetido a desgaste físico e mental33.

Uma pesquisa realizada com auxiliares deenfermagem no ambiente hospitalar estabeleceu um programa de educação com uma abordagem ergonômica e exercícios específicos. O programa envolveu educação com abordagem ergonômica e exercícios executados durante o horário de trabalho, duas vezes por semana, em um período de quatro meses. Os resultados mostraram uma diminuição estatisticamente significativa nafrequência de dor cervical, durante os últimos dois meses, e durante a última semana no grupo tratado. Houve também redução na intensidade da dor cervical em ambos os períodos e da dor lombar na última semana. Com base nesses resultados os aut ores sugerem um programa regular de exercícios, acompanhado $\mathrm{p}$ or abordagem instrucional ergonômica, para reduzir os síntomas musculoesqueléticos em tra balhadores de enfermagem ${ }^{34}$.

Destaca-se que não há como se falar em prevenção sem falar em conscientização e orientação. A enfermagem do trabalho tem uma função educativa que envolve o trabalhador com atividades a fim de promover o autocuidado, divulgando conhecimentos e estimulando a aquisição de hábitos sadios, no sentido de prevenir doenças profissionais e melhorar as condições de saúde do trabalhador. É interessante, portanto, que o enfermeiro do trabalho programe a realização de palestras informativas sobre LER/DORT, com vistas tanto à prevenção da doença quanto ao diagnóstico precoce ${ }^{35}$.

Por sua vez, compete à enfermagem as seguintes abordagens educativas: a) orientações em relação 
às técnicas adequadas de levantamento, manuseio e transporte de cargas e pacientes; b) orientações em relação à postura e movimentos, como por exemplo: evitar alcances excessivos, evitar o alongamento excessivo da coluna vertebral, utilizar escadinha ao retirar objetos de partes altas de estantes já construídas, armazenar objetos pesados dentro de uma amplitude de altura próxima à cintura e os objetos leves em qualquer altura situada entre o joelho e o ombro, colocar materiais em um nível que nunca ultrapasse a altura da cabeça; c) orientações em relação aos equipamentos e materiais, tais como: evitar a utilização de mobiliários e equi pament os i mprovi sados; d) ori ent ações organizacionais e psicossociais, como por exemplo:

\section{Considerações finais}

A prevenção das LER/DORT tornou-se um dos desafios a ser enfrentado na atualidade, sendo correto dizer que tais patologias são responsáveis por inúmer os casos de adoecimentos e afastamentos ao trabalho, gerando muitas vezes incapacidade parcial ou permanente, com aposentadoria por invalidez.

O processo de trabalho da enfermagem, por suas características, ocasiona o surgimento de lesões físicas relacionadas ao trabalho, muitas vezes irreversíveis. Considerando que as causas de LER/DORT estão relacionadas à atividade laboral, para prevenir é necessário mudar o trabalho, isto é, modificar as condições que podem potencialmente causar a doença. No trabalho da enfermagem a prevenção deve estar voltada às posturas adotadas pel os $\mathrm{t} r$ abal hador es na execução de suas atividades, mobiliários adequados ao cumprimento das tarefas, bem como a disponibilidade de instrumentos e equipamentos adequados, além da adoção de programas de treinamento e esclarecimentos sobre rotinas saudáveis.

Em relação à pesquisa de campo realizada para esta investigação, foi possível vislumbrar que os entrevistados possuem conhecimento sobre o problema e suas formas de prevenção. Mas, com a finalidade de aprofundamento, se faz necessária a educação continuada com esses profissionais de saúde sobre a LER/DORT, das situações de trabalho contínuo que favorecem o desencadeamento desses distúrbios musculoesqueléticos e sua prevenção.

Diante disso, percebe-se a necessidade de introducir esta temática na vida acadêmica dos discentes, com o intuito de despertar a consciência dos futuros profissionais sobre uma questão de extrema importância para a saúde do trabalhador, bem como adotar programas de treinamento e educação continuada, com a finalidade de possibilitar ao profissional de enfermagem o estabelecimento de estratégias para evitar o risco ocupacional e diminuir a probabilidade de manifestação da doença.

\section{Referências}

1. Magnago TSBS, Lisboa MTL, Souza IEO, Moreira MC. Distúrbios musculoesqueléticos em trabalhadores de enfermagem: associação com condições de trabalho. Rev. Bras. Enferm. 2007; 60(6):701-705.

2. Oliveira SCF. PREVDORT - Projeto de Prevenção de DORT. Disponível em:

http://www.ethos.org.br/.pdf. Acessado em: 16 nov. 2015.

3. O'Neill MJ. LER/DORT (Lesões por Esforços Repetitivos / Distúrbios Osteomusculares Relacionados ao Trabalho): o desafio de vencer. São Paul o: I nst i t ut o Naci onal de Pr evenção às LER/DORT, 2000.

4. Egri D. LER (DORT). Revista Brasileira de Reumatologia 1999;39(2):98-106.

5. Freitas JRS, Lunardi Filho WD, Lunardi VL, Freitas KSS. Distúrbios osteomusculares relacionados ao trabalho em profissionais de enfermagem de um 
hospital universitário. Rev. Eletr. Enf. 2009;11(4):904-11.

6. Moreira AMR, Mendes R. Fatores de risco dos Disturbios osteomusculares relacionados ao trabalho. Rev Enferm UERJ 2005; 13(1):19-26.

7. Rocha RM, Rossi CG, Alexandre NMC. Central de transporte de pacientes em hospital: um estudo post ur al e ergonômi co $r$ eal i zado com seus trabalhadores. Rev Enferm UERJ 2001;9(2):125-31.

8. Murofuse NT, Marziale MHP. Doenças do sistema osteomuscular em trabalhadores de enfermagem. Rev. Latino-Am. Enfermagem 2005;13(3):364-373.

9. Torres EO, Pinho DLM. Causas de afastamento dos trabalhadores de enfermagem em um Hospital do Distrito Federal. Comun Ciênc Saúde 2006;17(3):207-215.

10. Rocha AM, Silva MC, Chianca TCM. Causas de licenças para tratamento de saúde em um grupo de trabalhadores de central de material esterilizado de um hospital de Belo Horizonte. Rev Mineira Enferm. 2003;7(2):89-92.

11. Alves M, Godoy SCB, Santana DM. Motivos de licenças médicas em um hospital de urgênciaemergência. Rev Bras Enferm. 2006;59(2):195200.

12. Leite $\mathrm{PC}$, Silva $\mathrm{A}$, Merighi MAB. A mulher trabalhadora de enfermagem e os distúrbios osteomusculares relacionados ao trabalho. Rev. Esc. Enferm. USP 2007;41(2):287-291.

13. Renner JS. Prevenção de disturbios osteomusculares relacionados ao trabalho. Boletimda Saúde 2005; 19(1):73-80.

14. Minayo MCS. O desafio do conhecimento: pesquisa qualitativa em saúde. 8. ed. São Paulo: Hucitec/Abrasco, 2008.
15. Fernandes LA, Gomes JMM. Relatórios de pesquisa nas ciências sociais: características e modalidades de investigação. Disponível em: http:// 16 nov. 2015.

16. Richardson RJ. Pesquisa Social: Métodos e Técnicas. São Paulo: Atlas, 2007.

17. Trivinõs ANS. Introdução a pesquisa em ciências sociais: a pesquisa qualitativa em educação. São Paulo: Atlas, 2009.

18. Brasil, Ministério de Saúde. Conselho Nacional de Saúde, Resolução. 466/2012

19. Sakata RK. Lesão por esforços repetitivos doença osteomuscular relacionada ao trabalho (DORT). Rev. Bras. Med. 2001;58(4):77-83.

20. Lelis CM, Battaus MRB, Freitas FCT, Rocha FLR, Marziale MHP, Robazzi MLCC. Distúrbios osteomusculares relacionados ao trabalho em profissionais de enfermagem: revisão integrativa da literatura. Acta Paul Enferm. 2012;25(3):47782.

21. Couto HA, Nicoletti SJ, Lech O. Gerenciando as LER e os DORT nos tempos atuais. Belo Horizonte: Ergo, 2007.

www.seer.ufrgs.br/index.php/ConTexto/article/d ownload/1 1638/6840. Acessado em:

22. Ministério da Saúde (BR). Norma Técnica do INSS - Ordem de Serviço/INSS n. 606/1998. Brasília: Ministério da Saúde; 2001.

23. Gurgueira GP, Alexandre NMC, Corrêa Filho HR. Prevalência de sintomas musculoesqueléticos em trabalhadores de enfermagem. Rev Latino-am Enfermagem 2003; 11(5): 608-13.

24. Gallasch $\mathrm{CH}$, Alexandre NMC. Avaliação dos riscos ergonômicos durante a movimentação e transporte de pacientes em diferentes unidades hospitalares. Revista de Enfermagem UERJ 2003;11(3):252-260. 
25. Rosa AFG, Garcia PA, Vedoato T, Campos RG, Lopes MLS. Incidência de LER/DORT em trabalhadores de enfermagem. Acta Sci. Health Sci. 2008; 30(1):19-25.

26. Yeng LT, Romano MA, Teixeira MJ, Fernandes MM. Dorrelacionada ao trabalho: LER/DORT/AMERT. In: Teixeira MJ (org.).Dormanual para o clínico. São Paulo: Atheneu, 2006.

27. Alexandre NMC. Aspectos ergonômicos relacionados com o ambiente e equipamentos hospitalares. Rev. Latino-Am. Enfermagem 1998;6(4):103-109.

28. Silva RM, Rocha L, Tavares JP. Ergonomia: considerações relevantes para o trabalho de enfermagem. Disponível em: http://www.abennacional.org.br/.pdf. Acesso em: 20 jul. 2015.

29. Ministério do Trabalho e Emprego (BR). Norma regulamentadora $\mathrm{n}^{0} 17$. Disponível em: http://portal.mte.gov.br/legislacao/normasregula mentadoras-1.htm. Acessado em: 20 jul.2015.

30. Ministério do Trabalho e Emprego (BR). Norma regulamentadora $\mathrm{n}^{\circ} 32$. Disponível em:

http://portal.mte.gov.br/legislacao/normasregula mentadoras-1.htm. Acessado em: 20 jul.2015.
31. Raffone AM, Hennington EA. Avaliação da capacidade funcional dos trabalhadores de enfermagem. Rev Saúde Pública 2005; 39(4):669676.

32. Zilli C. Manual de cinesioterapia/ginástica laboral: uma tarefa interdisciplinar com ação multiprofissional. São Paulo: Lovise, 2002.

33. Alexandre NMC, Moraes MAA, Correa FilhoHR et al. Evaluation of a program to reduce back pain in nursing personnel. Rev. Saúde Pública 2001; 35(4):356-361.

34. Barboza MCN, Milbrath VM, Bielemann VM, Si que ir a $\mathrm{HCH}$. Doenças osteomusculares relacionadas ao trabalho (DORT) e sua associaçãocom a enfermagem ocupacional. Rev Gaúcha Enferm. 2008; 29(4):633-638.

35. Sznelwar LI. Fórum Nacional sobre o Fenômeno LER/DORT - "Construindo uma nova visão e formas concretas de ação". Ata final do Fórum. Florianópolis: Fundacentro, out., 2001.

Disponível na internet:

$<$ http://www.fundacentro.sc.gov $>$. Acessado em: 16 nov. 2015. 